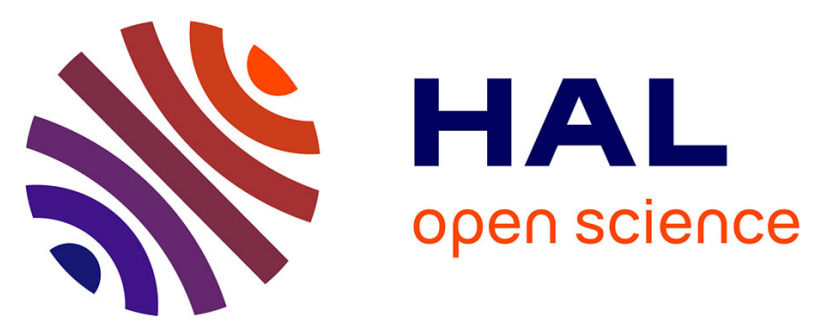

\title{
FP7 EU funded CORES wave energy project: a coordinators' perspective on the Galway Bay sea trials
}

Raymond Alcorn, Anne Blavette, Mark Healy, Anthony Lewis

\section{To cite this version:}

Raymond Alcorn, Anne Blavette, Mark Healy, Anthony Lewis. FP7 EU funded CORES wave energy project: a coordinators' perspective on the Galway Bay sea trials. Underwater Technology, 2014, 10.3723/ut.32.051 . hal-01266011

\section{HAL Id: hal-01266011 \\ https://hal.science/hal-01266011}

Submitted on 26 Jan 2018

HAL is a multi-disciplinary open access archive for the deposit and dissemination of scientific research documents, whether they are published or not. The documents may come from teaching and research institutions in France or abroad, or from public or private research centers.
L'archive ouverte pluridisciplinaire HAL, est destinée au dépôt et à la diffusion de documents scientifiques de niveau recherche, publiés ou non, émanant des établissements d'enseignement et de recherche français ou étrangers, des laboratoires publics ou privés. 


\title{
FP7 EU funded CORES wave energy project: a coordinators' perspective on the Galway Bay sea trials
}

\author{
Raymond Alcorn*, Anne Blavette, Mark Healy and Anthony Lewis \\ Beaufort Research, University College Cork, Cork, Ireland
}

Received 23 April 2013; Accepted 23 December 2013

\begin{abstract}
The present paper gives an overview of the lessons learnt from the project called Components for Ocean Renewable Energy Systems (CORES). In the context of this European funded $7^{\text {th }}$ Framework Programme research project, new components and systems for ocean energy devices were developed and trialed. The present paper also details the work packages, major achievements, significant impacts, summary results and the outcomes of the sea trials.
\end{abstract}

Keywords: ocean, wave energy, FP7, CORES, demonstration

\section{Introduction}

Components for Ocean Renewable Energy Systems (CORES) was an EU funded FP7 Collaborative Research Project and was coordinated by the Hydraulics and Maritime Research Centre in University College Cork (UCC). The Hydraulics and Maritime Research Centre is now integrated into UCC Beaufort Research since 2013.

The CORES project was intended to further develop components and systems required by the wave energy sector such as grid interface technology, power generators, moorings, instrumentation, telemetry and power control systems. The project started in 2008 and spanned over 3.5 years. It culminated with a three-month sea trial of the systems integrated onto the quarter-scale OEBuoy Hull in Ireland's Galway Bay Wave Test Site. This test site, which is operated jointly by Sustainable Energy Authority Ireland (SEAI) and the Marine Institute (MI), was made available at no cost to the project.

Thirteen partners from across seven European countries participated in the project. Although it concentrated on new concepts and components

\footnotetext{
* Contact author. E-mail address: R.Alcorn@ucc.ie
}

based on floating oscillating water column (OWC) systems, the majority of developments have relevance to most other wave device types.

The project finished successfully on budget, but was extended by six months owing to issues concerning weather conditions and vessel availability. How this was achieved, the lessons learnt and what pitfalls need to be avoided are addressed in the present paper. Techniques and tools developed to reduce the risk involved in prototype sea trials and planning, as well as resourcing methods, are discussed. Finally, the present paper details the intellectual property (IP) generated from the project that will be available to the wider ocean energy community.

The ultimate objective of the CORES project was to create a wave-to-wire modelling 'toolbox'. This toolbox would allow developers to evaluate the effect of changes in device components on the performance and economics of their devices. It was to consist of a number of numerical models or 'tools' developed within individual work packages and validated at bench scale and through laboratory scale testing at sea. Further information on these tools can be found in a number of detailed technical papers (CORES, 2011; Thiebaut, 2011) as well as on the CORES website (www.fp7-cores.eu).

\section{Project breakdown}

The project consisted of four work packages which represent a fully operational system as shown in Fig 1.

\subsection{Work package 1 (WP1): air turbines}

This work package focused on the design and manufacture of an alternative to the traditional, but 


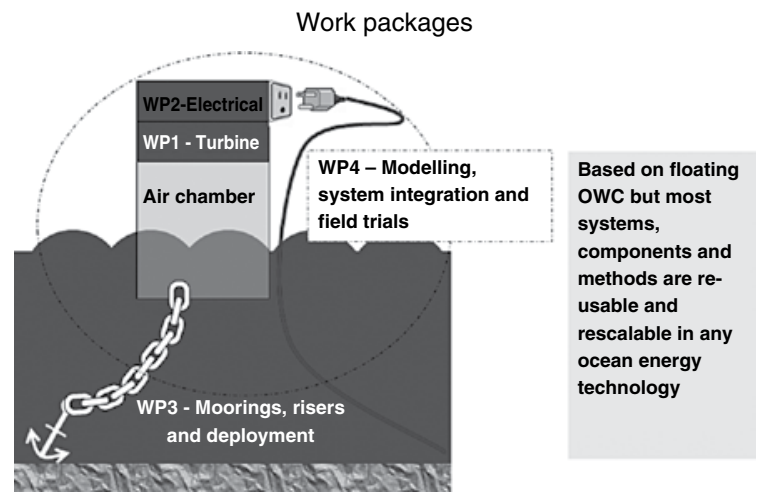

Fig 1: Subcategories of work package technical areas

limited, Wells air turbine system for OWC wave energy converters (WECs). The air turbine is a key element in the power conversion chain, as it is the primary converter from pneumatic power to mechanical power. Fig 2 shows the process for WP1 from specification to integration. This process took approximately 24 months as there were several iterations of design, influenced by a number of factors such as model results, tests results, budget constraints and patent issues.

\subsection{Work package 2 (WP2): electrical components and control}

This work package focused on all electrical components required for a wave device, concentrating in particular on the power take-off (PTO) system. The enhancement of the OWC WEC behaviour through the use of power electronics was investigated, with a special focus on optimising the operating envelope of the air turbine. Fig 3 shows the process from specification to integration for the electrical system and the uniqueness of the island grid system.

\subsection{Work package 3 (WP3): mooring, risers and deployment}

This work package addressed the design of mooring systems, as they can directly affect device performance as well as overall project costs. The moorings must be robust yet cost effective and easily deployable.

\subsection{Work package 4 (WP4): modelling, system integration and field trials}

This work package integrated the outputs from the previous three work packages. It culminated in system integration, sea trials and data acquisition which contributed to the development of an integrated modular wave-to-wire model toolbox.

During WP1, WP2 and WP3, concepts for various components of floating OWCs were designed, modelled and developed. In WP4, these components were integrated together on the Ocean Energy Buoy (the OE Buoy) floating OWC platform for three months of sea trials for testing as shown in Fig 4 (Johanning et al., 2008).

Some of the main achievements of the CORES project include the successful deployment of a wave energy device at sea for three months. In that time, the project achieved a validated turbine design methodology and an improved air turbine design for OWCs. It was also able to demonstrate a robust electrical system over three months of sea trials, and realised improved mooring design methods as well as a validated wave-to-wire model and PTO dynamic model.

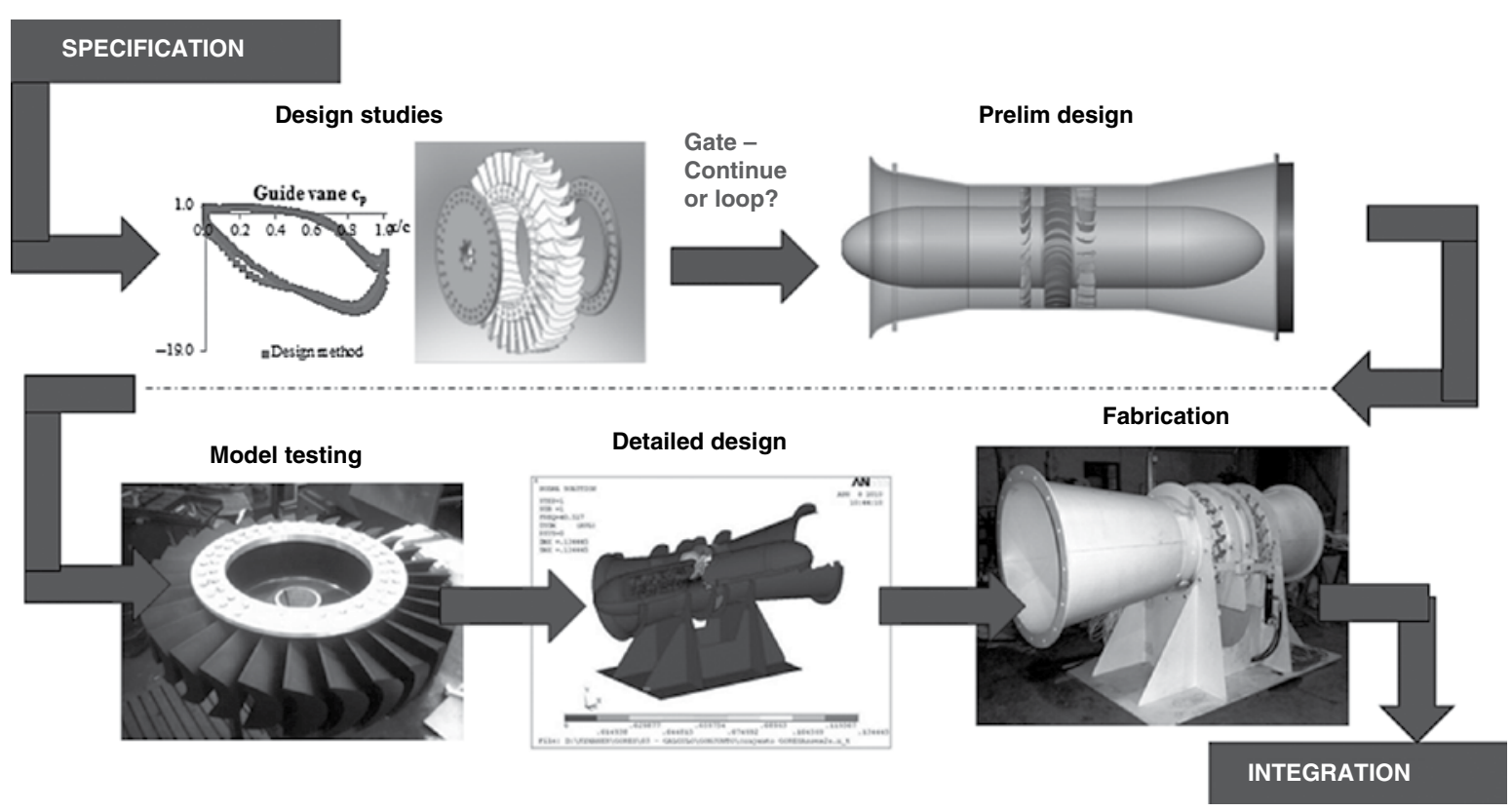

Fig 2: Air turbine research and development process 


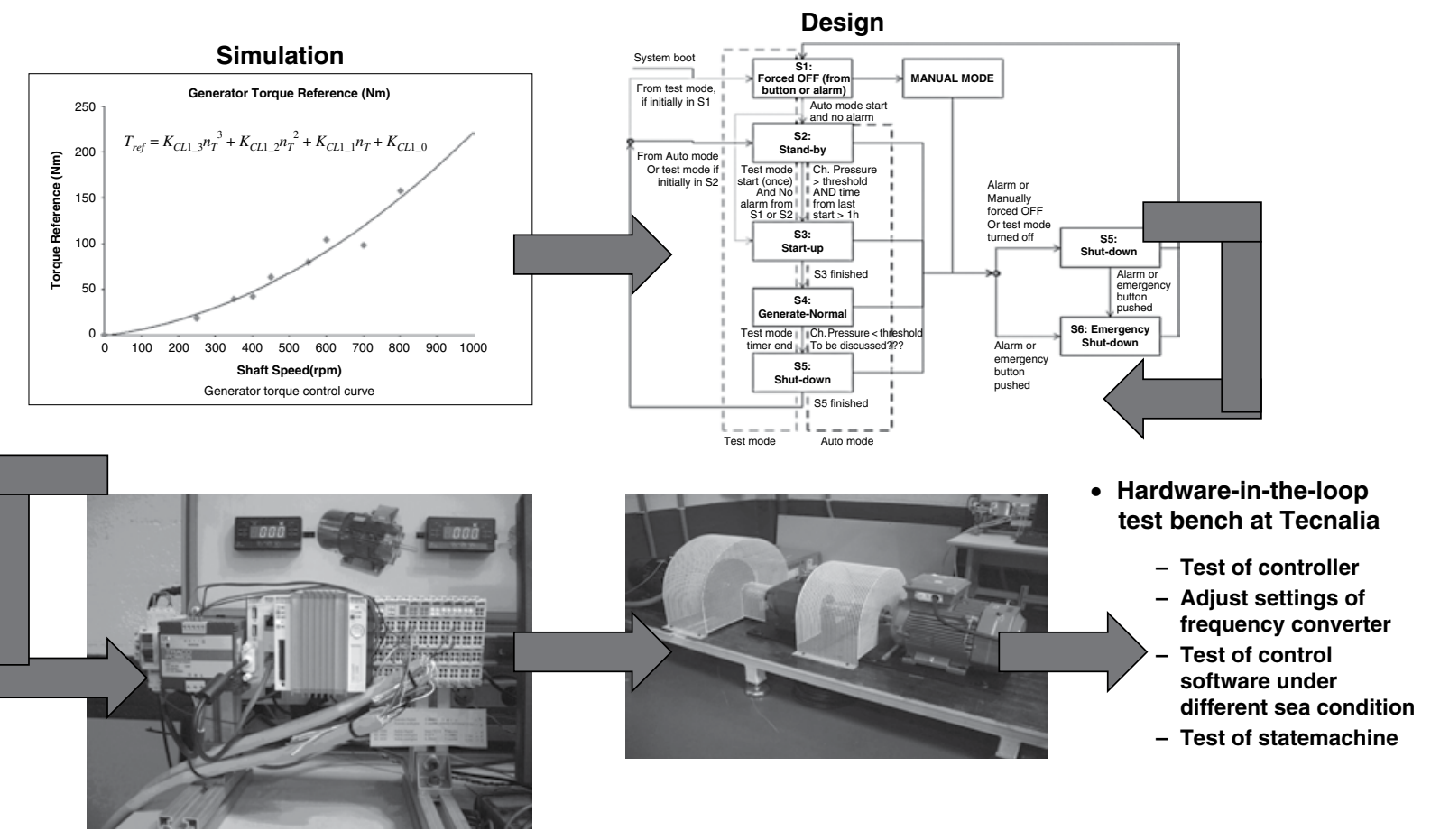

Fig 3: Electrical systems research and development process

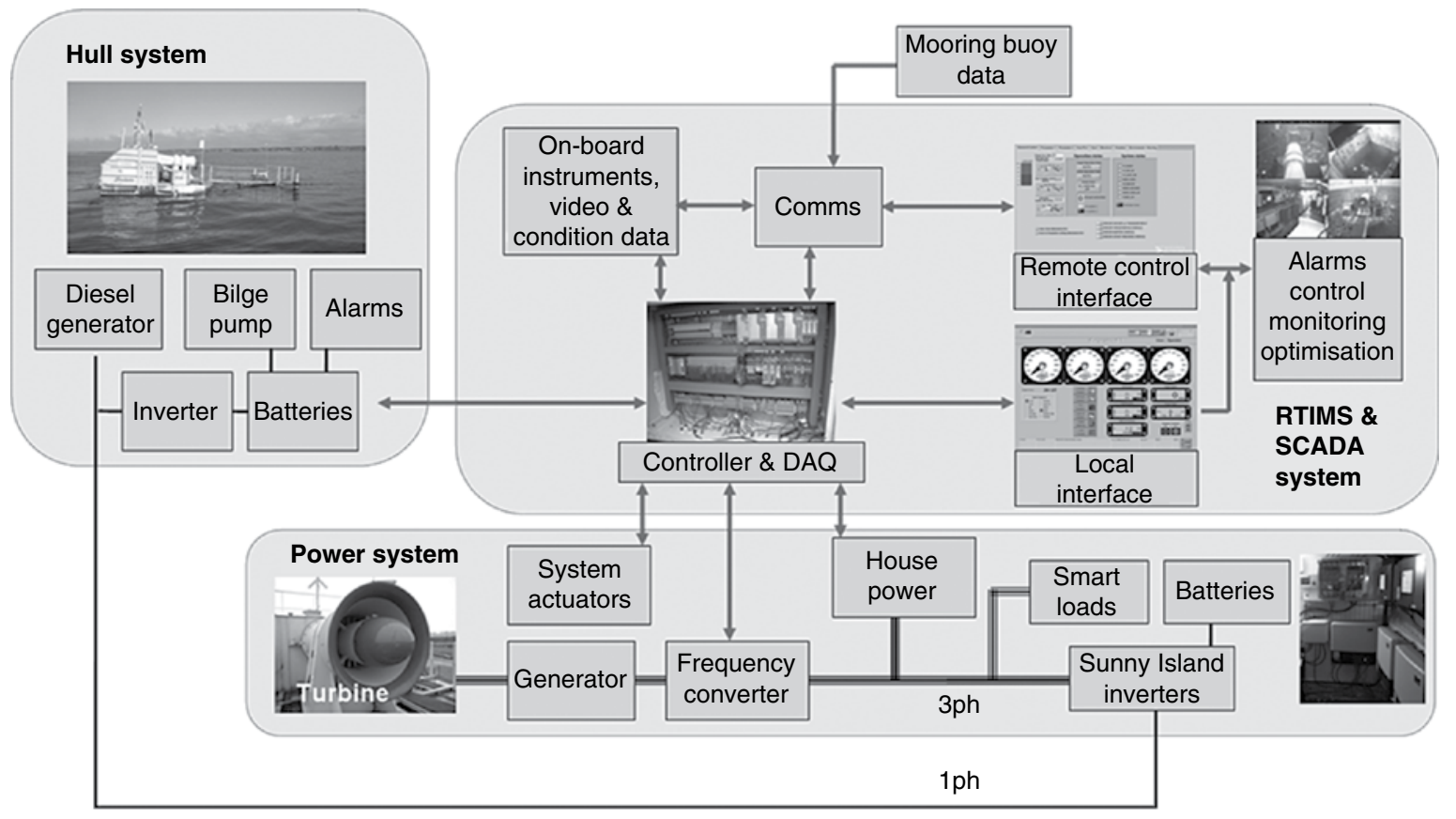

Fig 4: Schematic of a fully integrated system

\section{Project phases}

The project was broken down into a number of phases all culminating with the sea trials towards the end of the project. They are illustrated in Fig 5 .

As can be seen, each of the phases led to a fully functioning and integrated system at the end. Much of the R\&D at component level was done in the early stages, while the verification and validation were performed during the sea trials. However, one of the most important steps was the system integration and testing first in the Hydraulics and
Maritime Research Centre and then at dockside. This allowed the majority of system bugs to be ironed out in a controlled environment. Considerable time and effort was applied at these stages to simulate or synthesise expected normal and abnormal operating conditions, and to confirm that the integrated system was behaving as expected.

A number of documents were produced and circulated that allowed the entire project team to understand how the system would operate, who would operate it and what was to be tested. For 


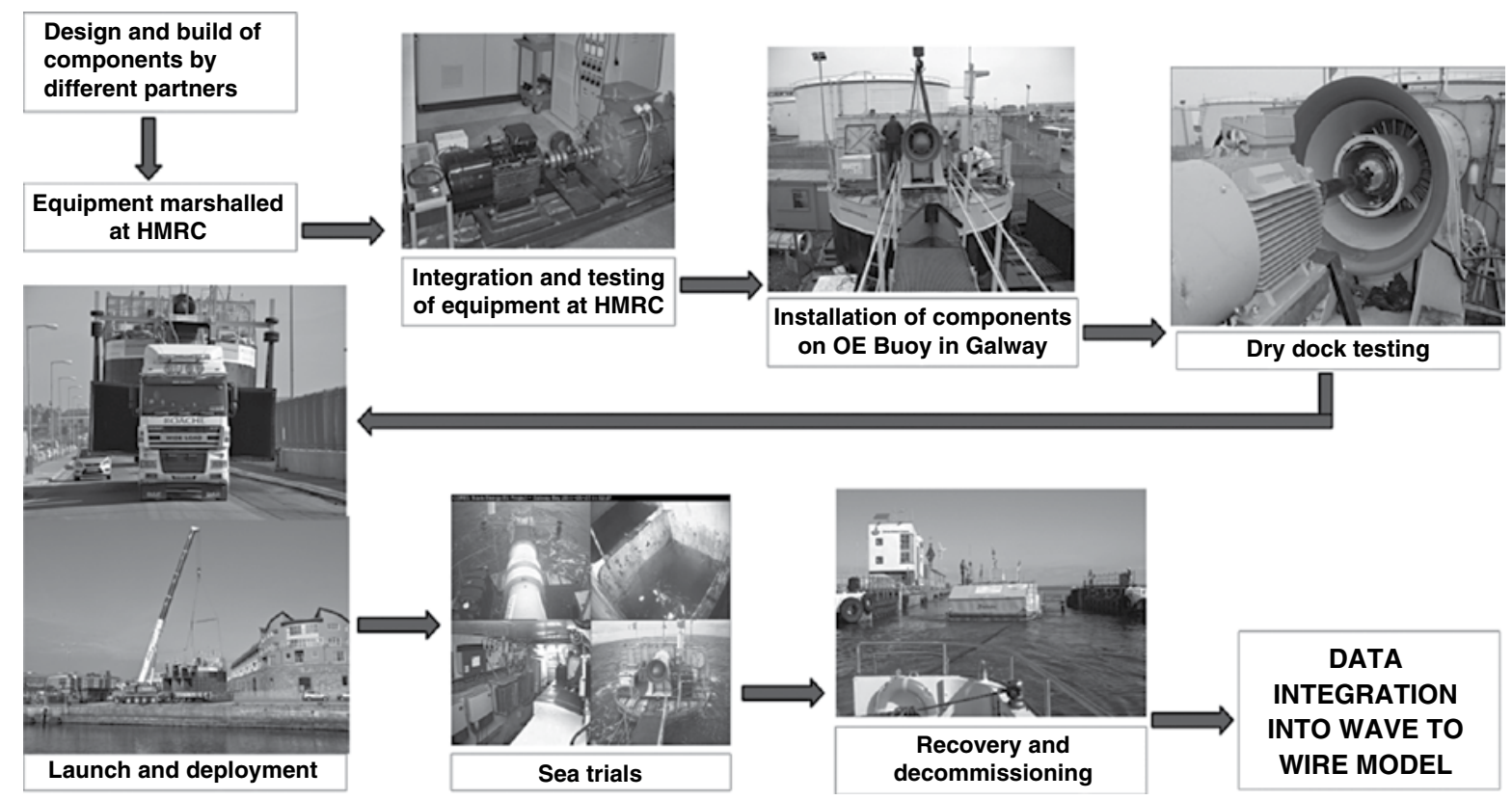

Fig 5: Phases of the project from concept through to validation

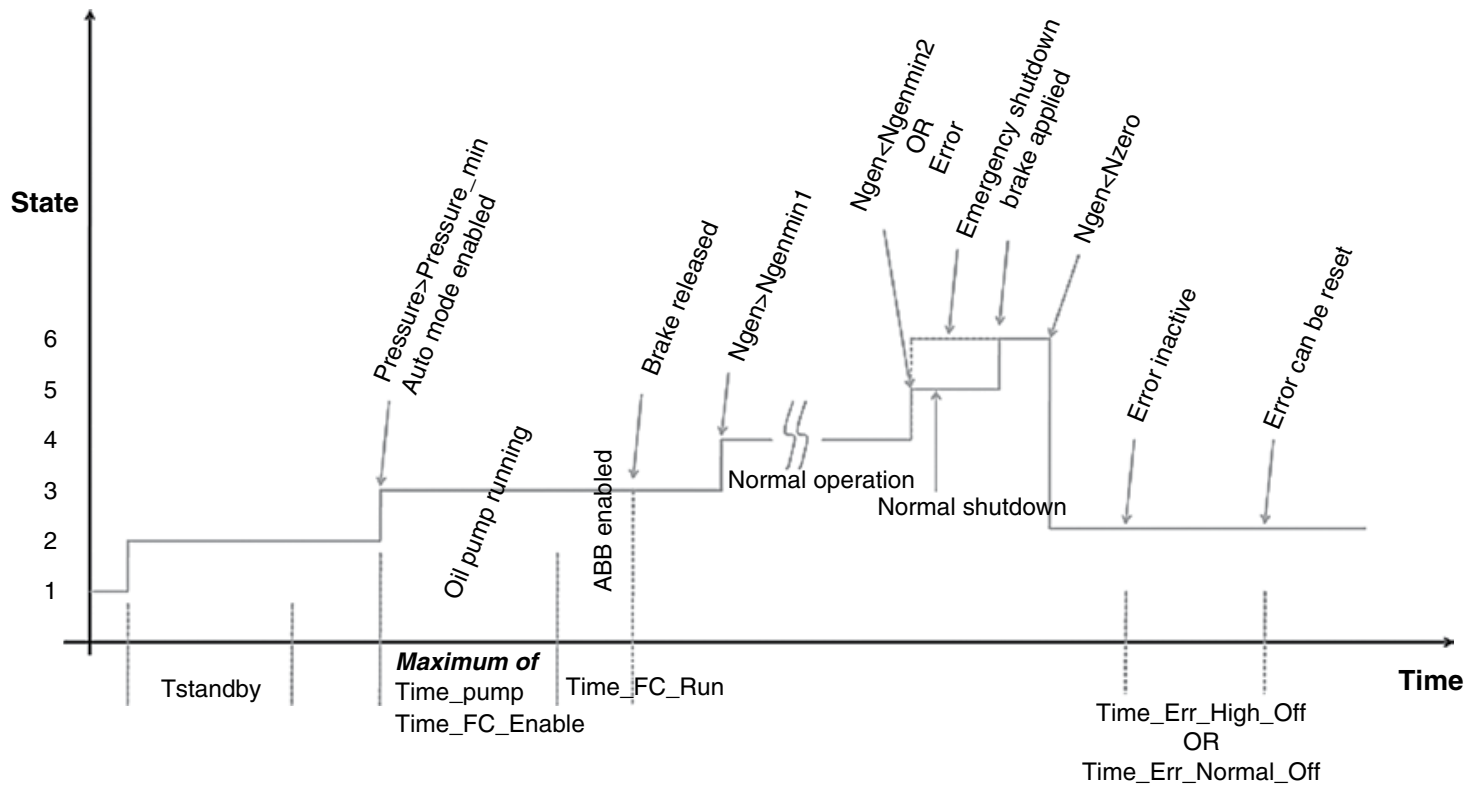

Fig 6: Example of a system state diagram as used in state machine control

example, the operational control document explained how the system would start up, run and shut down under any conditions and what would trigger a change from one state to the other. It described in detail the philosophy of how the on-board programmable logic controller (PLC) operated the plant with knowledge of its own state, the external environment and the requested inputs from the user. It also detailed various control laws that would be tested as well as remote, autonomous and failsafe operation modes. These mode states are illustrated in Fig 6.

A testing plan could then be developed with reference to the entire control system and control code. These could take the system through all conceivable scenarios and verify that it worked as it should.

It must be emphasised that many of the CORES team members had previous significant industrial experience of developing and operating such systems, which considerably accelerated the process.

Another significant document produced was the sea trials test schedule. This detailed all the tests over the three-month period that the CORES consortium wished to perform and the data it wished to generate which would allow validation and verification of the components tested. This document became the yardstick with which to measure the success of the project, as it allowed a fully objective view of its progress. 


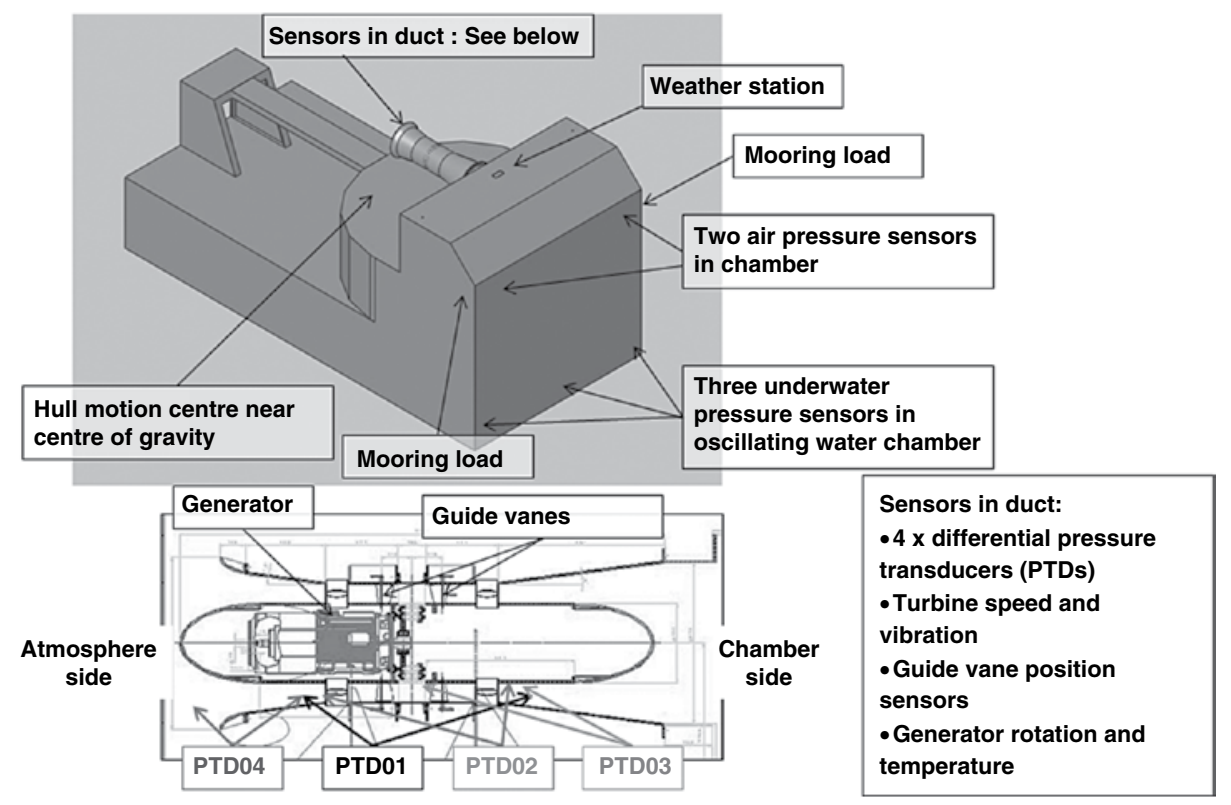

Fig 7: Schematic of sensor locations

These core operational and design documents were developed in a collaborative manner between the design teams in the different groups. This approach gave a strong foundation to the testing phase and avoided any potential misunderstandings or gaps from the outset.

\section{Sea trials}

During the sea trials, data were collected from over 200 sensors and system variables. Provided at the high temporal resolution of $0.1 \mathrm{~s}$, the data were then used to validate a number of numerical models of the different parts of the prototype, as well as to perform power system simulations (discussed later). Some of these are shown in Fig 7.

Operational data were available and all other data were collected, stored in a database and then transmitted to cloud storage. Data streams from external environmental sensors (e.g. wave riders and acoustic Doppler current profilers (ADCPs)) were post-processed, synchronised and added to the database. Owing to the amount of data, its exchange between the different partners of the project was facilitated by a query system that allowed the selection of specific data series with specific variables based on the system status, as shown in Fig 8 .

The data summary for the project is shown in Table 1.

\section{Generation of data for power system studies}

The prototype used in the frame of the project was connected to a small on-board island grid

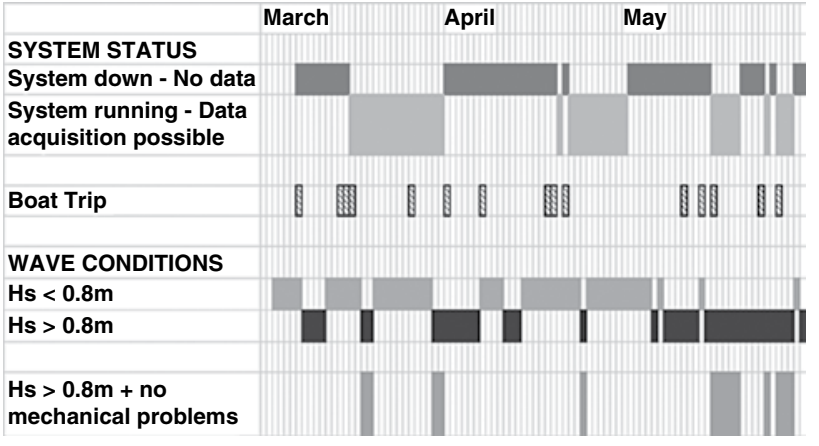

Fig 8: Time chart showing system and environment status

independent from the national electrical network, which was maintained by a fully rated power electronic converter. This type of converter enables the decoupled control of the generator from the grid and of the reactive power consumption of the system. Hence, it is expected to be widely used in grid-connected wave energy systems. The generated power was used to charge the on-board battery system, or was dumped in resistive load banks. A diesel generator was also included, as shown in Fig 9.

Table 1: CORES sea trials data summary

\begin{tabular}{lc}
\hline Status & Time (hours) \\
\hline In the water & 2,064 \\
System available data collected & 816 \\
Waves: Hs > 0.2m and system ON & 795 \\
Waves: Hs > 0.8m & 761 \\
Waves: Hs > 0.8m and system available & 192 \\
Constrained & 47 \\
Brake issues & 81 \\
Overheat & 2 \\
Charging & 22 \\
System generating & 36 \\
\hline
\end{tabular}




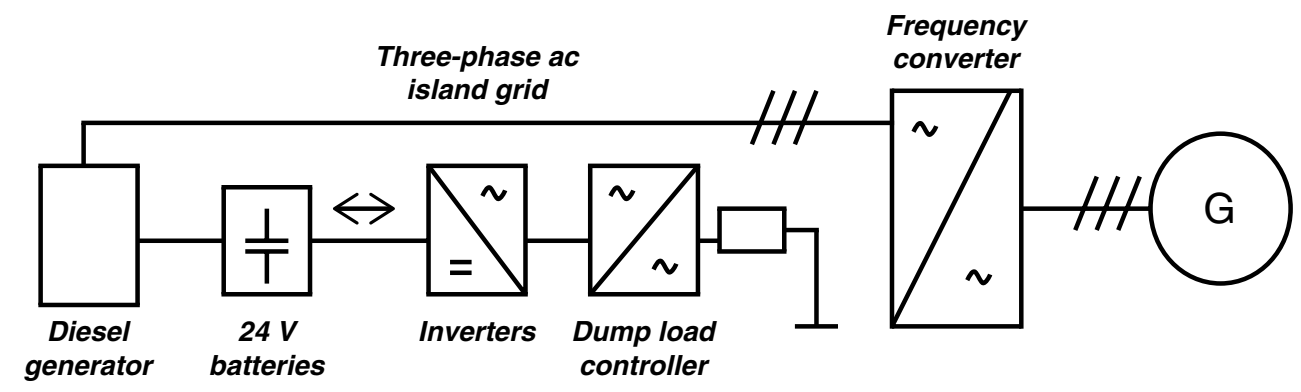

Fig 9: Electrical diagram of the on-board island grid

As mentioned earlier, the project has generated a considerable amount of time series data on a number of parameters, including electrical parameters at a high temporal resolution of 0.1 s. Contrary to most available data usually averaged over a sea-state, a season or even a year, the CORES electrical power time series data can thus be scaled and used directly for grid impact studies.

\section{Results}

As mentioned earlier, it is not possible in the present paper to detail all the achievements of project CORES, which instead can be found in the technical publications released as part of the project. However, this section provides some of the highlights.

First, it achieved an improvement on average efficiency over conventional designs leading to a lower cost/kWh ratio. In fact, the CORES project produced the most efficient air turbine to date, with average cycle efficiencies up to $65 \%$ when tested in both laboratory and real-world conditions (see Fig 10).

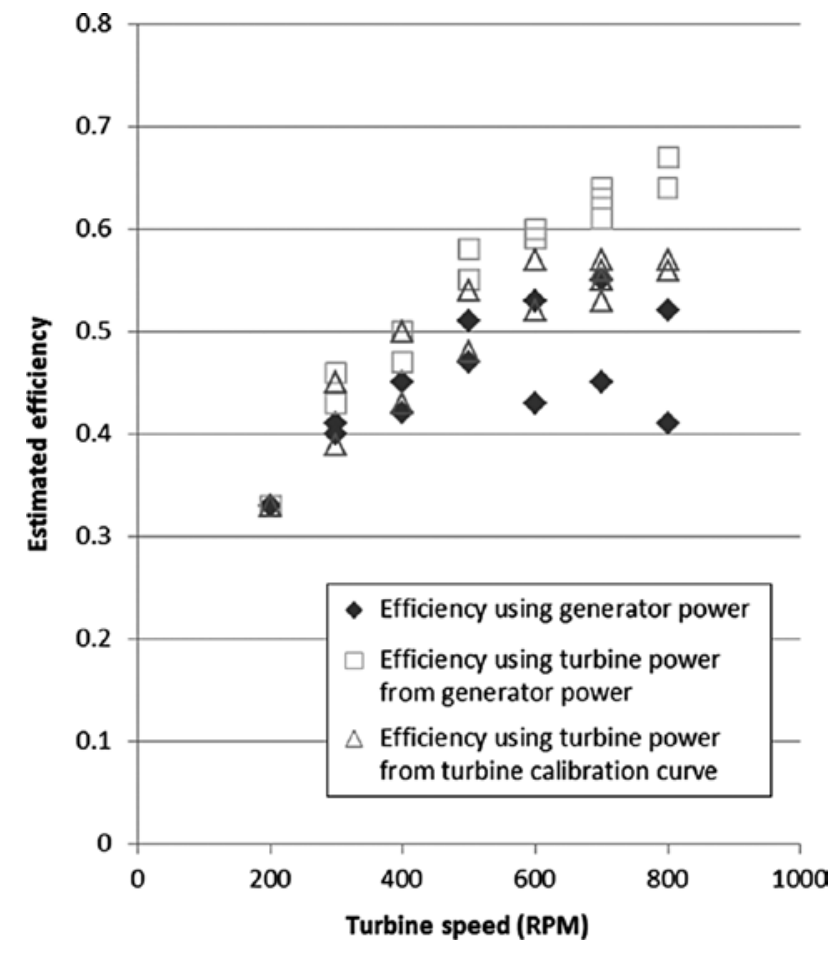

Fig 10: Turbine efficiency chart
In addition, more precise physical modelling of the mooring system and umbilical cables, as well as with numerical simulations, was achieved through 2D tests in Università di Bologna (Italy) and 3D tests in the Hydraulics and Maritime Research Centre (Ireland) (Martinelli et al., 2009; Martinelli et al., 2010a,b). A typical mooring test is shown in Fig 11.

Finally, it succeeded in developing suitable power smoothing algorithms to reduce the impact that a wave farm may have on weak grids. Such types of grid can be found off the west coast of Ireland and off the north coast of Scotland, where the most abundant wave resources in Europe are located. Hence, these algorithms can greatly increase market potential for the wave devices. Shown in Fig 12 is an example from the CORES prototype power output using a control algorithm that did not smooth the power.

\section{IP generated}

A considerable amount of IP, software and knowhow was generated through the CORES project that can be accessed via the consortium members. Much of the IP is owned jointly and agreements are being put in place for its exploitation, so shortly it will become available to the industry as a whole. A non-exhaustive list with the respective joint owners is given in Table 2.

\section{Coordinators overview}

\subsection{Project management}

As with any significant engineering project, good project management was crucial to the success of this project. Some challenges regarding the sea testing of wave energy devices are unique, even more so when there are a large number of partners from across the EU involved in developing components for the device. This section covers the key points that can be taken from the sea trials of the OE Buoy as part of the CORES project.

Comprehensive test plans are required for testing prior to deployment and during the sea trial phase of a device. This was particularly important for this 

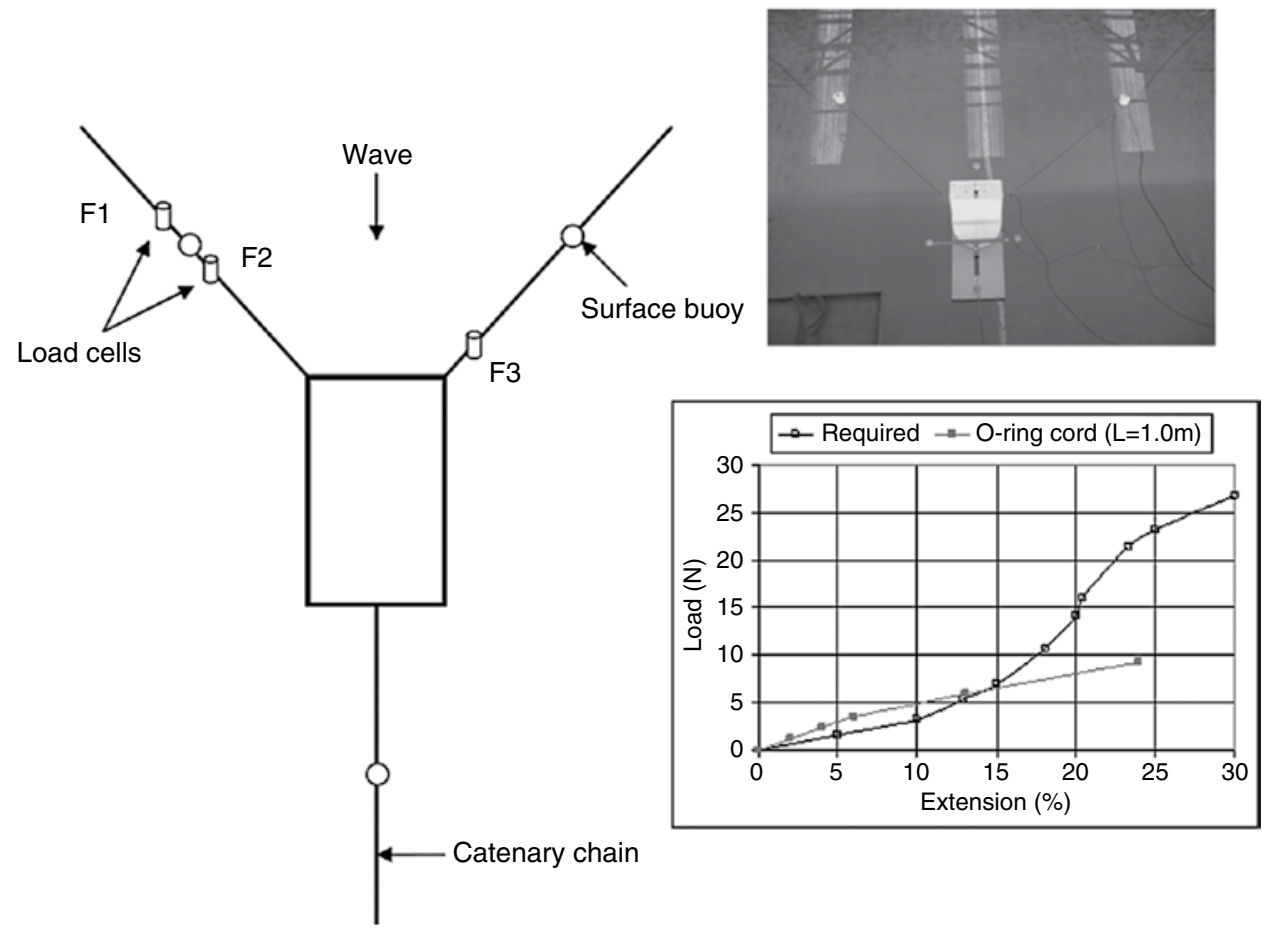

Fig 11: Example of a mooring test and its related data

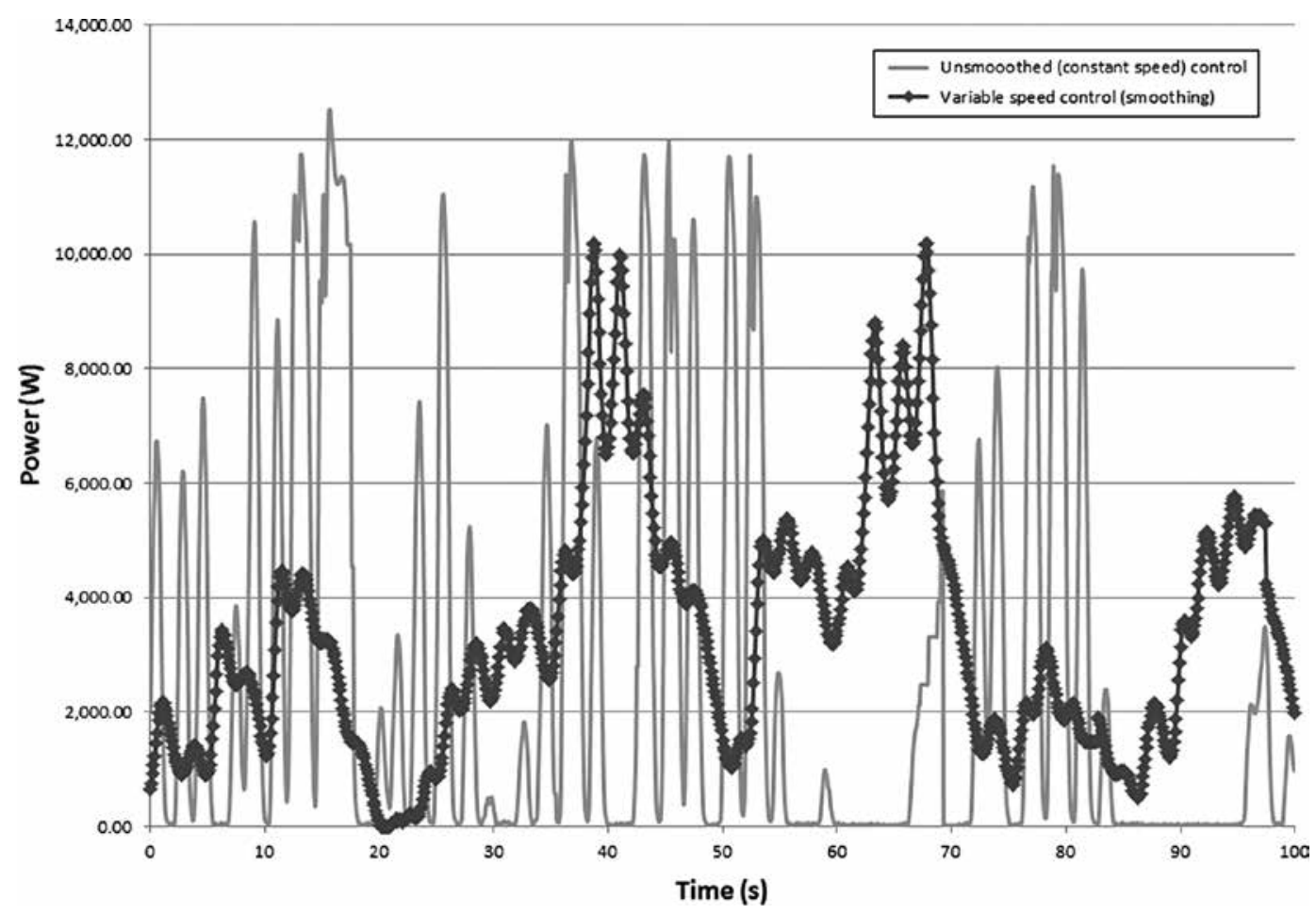

Fig 12: Device power output performance (unsmoothed and smoothed)

project, especially for the Galway dock testing when there were many people onsite working on different elements of the design. Hence, testing that had been undertaken could be tracked and future tests planned out.

A large amount of equipment (mechanical, electrical, sensors, data acquisition, etc.) also needed to arrive in Galway within a short time period. Most equipment was first marshalled at the Hydraulics and Maritime Research Centre premises and was then delivered successfully at Galway for installation on the buoy.

An onsite office was set up at the dockyard in Galway and provided an important base during installation and testing of the CORES components. This phase of the project involved long days onsite 
Table 2: IP generated through the CORES project and joint owners

\begin{tabular}{ll}
\hline IP & Owners \\
\hline Mooring modelling and simulation & MCS Kenny, University of Exeter \\
Mooring instrumentation & University of Exeter \\
Air turbine aerodynamic design & Instituto Superior Technico (IST) \\
Air turbine mechanical design & Kymaner \\
Power take-off system design and build & UCC_HMRC, Fraunhofer IWES, Tecnalia \\
On-board stand-alone micro-grid, grid control design and build & UCC_HMRC, Queens University Belfast (QUB) \\
Control system design and operation & UCC_HMRC, Fraunhofer IWES, Tecnalia, QUB \\
Data acquisition & QUB, UCC_HMRC \\
System and instrumentation & QUB, UCC_HMRC, Fraunhofer IWES \\
System integration & UCC_HMRC, Fraunhofer IWES, QUB \\
Onshore operation planning, and management & UCC_HMRC \\
Offshore operation planning, and management & UCC_HMRC, Ocean Energy Ltd \\
Onshore commission & UCC, QUB, Kymaner, Fraunhofer IWES, Tecnalia \\
Offshore commission and operation & UCC, Fraunhofer IWES, QUB \\
Wave-to-wire model & Wave Energy Centre and most others \\
\hline
\end{tabular}

during which the office was able to provide an internet connection and phone charging facilities to maintain communications and an area onsite to plan and review work.

The launch of the platform, towing it to the Galway Bay test site, installing it and the subsequent recovery were difficult tasks. The previous experience and knowledge that OE Ltd had of Galway Bay were invaluable to ensuring that these tasks were completed without any problems. In addition, Galway Harbour had a good supply of lifting equipment that may not be available in other harbours.

The knowledge of OE Ltd of the sea conditions in Galway Bay was valuable in ensuring that all trips to the OE Buoy were completed safely. Project safety was also helped by the provision of sea survival training to members of the Hydraulics and Maritime Research Centre staff involved in visits to the test site.

The Galway Bay test site is conveniently located in comparison to some other test sites. Difficulties that were not encountered there may be encountered at more isolated test sites like Belmullet, where electrical supplies and accommodation may not be as readily available and weather windows for deployment and access to devices may be shorter.

The Hydraulics and Maritime Research Centre, QUB and Fraunhofer IWES staff were willing to work long days and through the night and be on phone standby at different stages during the sea trials. Both the Hydraulics and Maritime Research Centre and QUB staff were prepared to travel to Galway at short notice in order to rectify problems that occurred during the sea trials.

During the sea trials, a plan and rota were required for the monitoring of the device within the Hydraulics and Maritime Research Centre and with Fraunhofer IWES and QUB. This monitoring plan worked very well, in particular during periods when 24-hour monitoring was required.

Certain aspects of the CORES project management could have been improved, and the following paragraphs highlight aspects that should be considered for future sea trials of wave energy devices.

With so many partners involved with those working on the project exceptionally busy at certain times, it was sometimes difficult to keep all partners up to date with the progress of the project and to share data with them (Kelly et al., 2012). A public human machine interface that all users would have access to without disrupting those monitoring the buoy would have been a useful addition.

Another challenge was the accessibility and frequency of the boat trips to the test site. While using Ocean Energy Ltd to arrange boat trips was good in terms of safety and its local knowledge, at times it left the Hydraulics and Maritime Research Centre unable to reach the test site when they were required. This may have been overcome if another local boat could have been used for some of the boat trips.

In addition, there were constraints on the launch and tow-out times at Galway Harbour, as the gates can only be opened at high tide level. These constraints had to be kept in mind when looking at weather windows suitable for towing out in Galway. There were also constraints on the tow-out date owing to the availability of tug boats suitable for towing the device. This equipment needs to be arranged well in advance and influences deadlines for work necessary prior to device deployment.

\subsection{Technical}

A number of technical lessons were learnt from the project. Again, these are detailed in other publications but some of the highlights are as follows: 
- A phased approach to equipment testing and equipment integration is critical to the risk associated with an offshore project in the research phase.

- Installation of multiple, redundant sensors is extremely important for maximal data output and equipment protection.

- A full load profile from design data or validated simulation sets for critical components minimises the risk of operational failure.

- Cost saving through re-use of equipment results inevitably in a net loss.

- Operational failure risk is minimised through robust process control with a sophisticated alarm and error handling methodology.

- Remote reset capability should be designed in all control elements.

- Scope boundaries and interface management cannot be underestimated from a physical, financial, insurance, operational and risk perspective.

\section{Conclusions}

The conclusions of the project from the coordinators' viewpoint are:

- 2064 hours in the water, 816 hours of data collected, 795 hours during which the significant wave height Hs was greater than the threshold for data collection.

- Validated turbine design, which performed better than expected.

- Validated electrical methodology and optimised control strategies.

- Validated mooring loads.

- Remote control, DAQ and HMI proven.

- Cost-effective data management strategy.

- Validated wave-to-wire model.

- No discernible environmental impact.

- Verified design, integration testing and sea trial methodologies.

- Scalable industrialised systems.

These were achieved by:

- The consortium, as all the team members had industrial experience.

- Proper planning (measurable progress and targets), through the use of key project management tools.

- Phased development and factory/dockside testing to decrease risk (though, even so, problems must be expected and a reaction plan must be prepared).

- Need for staff and a monitoring rotation.

- Remote access and control (which was critical).
- An industrial approach (which made it possible to complete a real sea trial of wave energy device on time and within budget).

\section{Acknowledgements}

The research leading to these results has received funding from the European Community's $7^{\text {th }}$ Framework Programme (FP7/2007-2013) under grant agreement $\mathrm{n}^{\circ} 213633$ (CORES project).

The authors would like to acknowledge the contributions from all of the CORES consortium members: University College Cork (Coordinator), Ocean Energy Ltd., MCS Kenny, University of Limerick, Queen's University Belfast, University of Exeter, Fraunhofer IWES, Kymaner, WavEC, IST, Tecnalia, University Aalborg and University of Bologna.

The authors would also like to acknowledge the help and support received from the Marine Institute and from the Sustainable Energy Authority of Ireland-Ocean Energy Development Unit, who made the Galway Bay test site and its sensor data available for the duration of the sea trials.

\section{References}

CORES Consortium. (2011). Final publishable summary report, contract no. 213633. Available at www.fp7-cores. eu, last accessed $<10$ January 2014 $>$.

Johanning L, Spargo AW and Parish D. (2008). Large scale mooring test facility: A technical note. In: Proceedings of the $2^{\text {nd }}$ International Conference on Ocean Energy, 15-17 October, Brest, France.

Kelly J, O'Sullivan D, Alcorn R and Lewis AW. (2012). Challenges and lessons learned in the deployment of an offshore oscillating water column. In: Proceedings of the International Conference on Ecological Vehicles and Renewable Energies (EVER), 25-28 March, Monaco.

Martinelli L, Lamberti A and Ruol P. (2009). Second-order drift forces on 'offshore' wave energy converters. In: Proceedings of the COMSOL conference, 10-12 October, Milan, Italy.

Martinelli L, Spiandorello A, Lamberti A and Ruol P. (2010a). Dynamic model for catenary mooring: experimental validation of the wave induced load. In: Proceedings of the COMSOL conference, 17-19 November, Paris, France.

Martinelli L, Lamberti A, Ruol P, Ricci P, Kirrane P, Fenton $\mathrm{C}$ and Johanning L. (2010b). Power umbilical for ocean renewable energy systems - feasibility and dynamic response analysis. In: Proceedings of the $3^{\text {rd }}$ International Conference on Ocean Energy, 6 October, Bilbao, Spain.

Thiebaut F, O‘Sullivan D, Kracht P, Ceballos S, López J, Boake C, Bard J, Brinquete N, Varandas J, Gato LMC, Alcorn R and Lewis AW. (2011). A floating OWC device with movable guide vane impulse turbine power take-off. In: Proceedings of the European Wave and Tidal Energy Conference series, Southampton, UK. 